\title{
A proposed framework of sustainable self-evaluation maturity within companies: an exploratory study
}

\author{
Reidson Pereira Gouvinhas ${ }^{1}(\mathbb{D})$ Tatiana Reyes $^{2} \cdot$ Ricardo Manfredi Naveiro $^{3}$. \\ Nicolas Perry ${ }^{4} \cdot$ Eduardo Romeiro Filho $^{5}$
}

Received: 25 May 2016 / Accepted: 1 June 2016 / Published online: 13 June 2016

(C) Springer-Verlag France 2016

\begin{abstract}
Companies are still struggling to implement ecodesign in their daily product development processes. It is believed that this occurs because companies should firstly improve their strategy and management skills towards sustainability before introducing any ecodesign tool. As a consequence, this paper aims to propose a self-evaluation framework to rank companies into different classes according to their level of maturity in terms of sustainability. It also discusses "minimum requirements" to move from one level to another towards sustainability. This will help companies
\end{abstract}

Reidson Pereira Gouvinhas

reidson@ct.ufrn.br

Tatiana Reyes

tatiana.reyes_carrillo@utt.fr

Ricardo Manfredi Naveiro

ricardo.naveiro@poli.ufrj.br

Nicolas Perry

nicolas.perry@ensam.eu

Eduardo Romeiro Filho

edu.romeiro@gmail.com

1 DEP/CT/Universidade Federal do Rio Grande do Norte, Campus Universitário, Lagoa Nova, Natal, RN 59078-970, Brazil

2 ICD, Pôle HETIC, CREIDD, Université de Technologie de Troyes, UMR 6281, CNRS, Troyes, 12 rue Marie Curie, Troyes 10010, France

3 PEP/COPPE-Universidade Federal do Rio de Janeiro, Cidade Universitária-Centro de Tecnologia, 21941-909 Rio de Janeiro, Brazil

4 Arts et Metiers ParisTech, I2M-UMR 5295, 33400 Talence, France

5 LIDEP-DEP-UFMG-Escola de Engenharia, sala 3104. Av. Antônio Carlos, 6627, Belo Horizonte, MG 31270-901, Brazil to better understand which strategic and managerial actions they need to take before implementing any ecodesign.

Keywords Ecodesign - Sustainable self-evaluation · Maturity framework

\section{Introduction}

Corporate sustainability is nothing more than handling the business taking into account the sustainable development into its three fundamental principles: environmental protection, economic stability and social responsibility [1]. A literature review has indicated many reasons why companies should look to corporate sustainability to become more competitive [2-6].

As a consequence, the global sustainability awareness has evolved to a point where businesses must consider the impacts of their processes and products throughout their life-cycle and supply chains. Unfortunately, in general, this process occurs in a heuristic manner, based on previous experience and general guidelines without the assurance that the designer will get a significant result [7], and most of the time without a complete rethinking (and involvement) of all the supply chain. It follows that the product development activity is too risky for the product commercial success and it requires a suitable planning by the company. As a consequence, it is believed that there is a need to improve the integration of sustainable issues into design within all company activities: from strategic decision-making to the end of the final project. In addition, companies need to better integrate the relationship between general corporate development and eco-design activities. 


\section{Research gap}

A review on the literature has suggested many ways to deliver sustainability into companies [8-14] as well as has shown specific companies which have already tried to achieve that [15]. However, despite of these efforts, it seems that research on sustainability is presented on a widespread manner which indicates that the simple application of eco-innovation solutions, eco-efficiency and corporate responsibility practices alone are insufficient to deliver the holistic changes necessary to achieve a long-term social and environmental sustainability within companies [16]. In other words, creating a sustainable corporate image it is not only a matter of developing some "sustainable products". It also requires that all management procedures within the company are based on a different philosophy and strategic vision towards sustainability. This new vision should permeate all company sectors and departments. This is particularly true for companies who are still struggling to implement ecodesign in their daily product development processes (PDP).

Therefore, our research argues that this gap occurs because companies should firstly improve their strategy and management skills towards sustainability before introducing any ecodesign tool. In other words, companies should improve the social environmental aspects of their products by considering a collaborative work among the entire organization. This involves not only the three levels of the company (strategic, tactical and operational) but also its stakeholders [17]. In order to achieve this goal, a cultural change within the entire organization towards sustainability is required [18].

As a consequence, to become more effectively, the PDP should be integrated into a broader framework within the organization in a holistic manner. This means that decisions taken during the development of the product should reflect other decisions taken at the strategic, tactical and operational levels and vice-versa. The decision process can be carried out "top-down" (from strategy to operational level), "bottom-up" (from operational to strategy level) as well as "middle-two sides" (from tactical to strategy and operational levels) in a complete synergy which involves the organization as whole $[19,20]$.

This is a long process which demands patience and time to be completed and does not occur in a uniform manner within the entire organization. Some departments or sectors within the company may maturate these ideas quicker than others. As a consequence, the level of sustainable maturity may vary from one department to another and also at the different levels of the organization (strategic, tactical and operational) as well as among their personnel [21,22].

Engert et al. [23] argue that with respect to the strategy formulation and implementation, strategies can be either intended and deliberate or emergent.
In this paper, we are particularly interested in emergent strategy. This means that some organizations begin implementing strategies before they clearly articulate mission, goals, or objectives. In this case strategy implementation actually precedes strategy formulation [24].

In addition, it seems that corporate sustainability is extremely complex once its parameters (e.g. technology, regime and visibility) may vary across industries, plants, countries and different point in time [25].

Engert et al. [23] highlight the lack of effort regarding the development of potential solutions to integrate corporate sustainability dealing with complexity. "The integration of Sustainability assumes that a related strategic decision needs to be taken. This is essential for generating a sufficient level of company-wide commitment" [23]. For example, Rossi et al. [26] claim that despite the great number of existing ecodesign tools and methods, also in commercial tools available, companies still have difficulty in their practical and effective implementation and use. They also argue that new sustainable models should be based of the real needs of industrial companies, which at the moment are not included for example in the methods of development process.

Therefore, there must be a change on the way business is carried out. Companies should be able to review their business models to pursue a proactive attitude towards environmental regulations and incentives as well as market demands. In addition, consumers have to drastically change their approach to their consumption behavior. As a consequence, they may take part on the product development process themselves.

\section{Research objectives}

This research proposes to develop an easy to use, not time consuming and suitable for all type of organisations self-evaluation framework to rank companies into different classes according to their level of maturity in terms of sustainability.

This self-analysis will help companies to better understand which actions they need to take before implementing any ecodesign tool as well as to select which tool is more appropriate to their situation.

The paper also discusses the "minimum requirements" that a company needs to attend before moving from one level to another showing a step-by-step evolution towards corporate sustainability.

\section{Research methodology}

Blessing and Chakrabarti [27] argue that "Design research" (i.e. the study on how to research design) can be classified 
into three different main areas: Descriptive studies I and II as well as Prescriptive study (PS).

Descriptive study I(DS-I) aims to increase the understanding of design and its successful factors by investigating the phenomenon of design through reviewing the literature about empirical research, undertaking empirical research, and, in addition, through reasoning. Prescriptive study (PS) indicates on how to develop a support to improve the design process, and Descriptive study II (DS-II) focuses on the evaluation of these different types of supports for the design process.

In this paper, the term "support" can be used to describe simple guidelines, any design methodology, methods or tools to improve the design process.

The authors argue that DS-I aims to understand an existing situation to provide suggestions for the support in order to improve the design process while DS-II aims to understand a situation in which the support is introduced, in order to assess its ability to improve the existing situation and to provide suggestions for improvement of the support.

Therefore, the proposed framework of this study can be classified as a DS-I once we propose a framework to understand how companies deal with aspects related to sustainability before introducing any ecodesign support.

In order to achieve the research aims, the following research methodology approach is divided into FOUR phases as follows:

- The initial stage of the research methodology is based on an extensive literature review. At this point, a number of different corporate sustainability models were analyzed (please, see Sect. 5). This phase was useful to enable a better understanding regarding theories supporting corporate sustainable businesses;

- Based on the literature review, a framework is developed aiming to evaluate companies in terms of their level of corporate sustainable maturity. The framework is based on a questionnaire in which decision-makers from different areas of the organization (strategy, tactical and operational) will evaluate a series of statements against five aspects. According to the answers given, the framework generates 12 indicators which will be used to create a general index $I$. The value of this general index will then be used to rank companies into six levels of sustainable maturity.

- The next step is to carry out an initial testing and validation of the proposed framework. Based on that, ten manufactured companies were randomly selected and invited to answer the questionnaire. The proposed of this phase was to "pilot" the questionnaire to verify of it is well understandable and if it deliveries the results we expect from the framework.

- The following step is to make some improvements on the questionnaire as well as the framework in general. Once completed, the framework will be applied to companies in France and Brazil for comparison.

At the moment, the research is under the THIRD step (i.e. initial testing and validation of the framework) and improvements within the questionnaire and framework will take place. More details on how the framework was built and how it works will be given in the Sect. 6 .

\section{A maturity framework towards sustainability}

Many frameworks aiming to introduce sustainable issues within different sectors of the economy have been proposed by the literature.

For instance, some of them are mainly focused on a national, regional or community level [28] while others are business level [29-31]. In addition, global reporting initiative (GRI) uses a hierarchical framework consisting of categories, aspects and indicators [32].

Nevertheless, some frameworks concentrate their efforts on one aspect of sustainability, such as corporate social responsibility (CSR) [28].

However, most of these frameworks are very complicated as well as time consuming and require some expertise to be performed [33].

Another group of frameworks is more related on improving sustainable products and services. For instance, Carlson and Rafinejad [34] developed a framework that enables companies to consider the impact of their product development process on future resource and environmental conditions (e.g. taking into account how a product can be designed for reuse and recycling). In addition, the Sustainability Maturity Model Research-on-Research (ROR) [35] focuses primarily on the activities performed by Research and Development (R\&D) department and New Product Development (NPD) functions or activities performed by other functions that support technology research and NPD. Also, the Ecodesign Maturity Model is a management framework based on a step-by-step approach aiming to support companies to carry out ecodesign implementation [19]. Its application comprises into six steps, including a set of face-to-face interviews with the selected employees.

However, all of these proposed frameworks concentrate their efforts only on improving products and services or on the product development process itself in terms of sustainability. It is believed that they should go beyond into their analysis by proposing a holistic description on "how a firm does business" [36]. This vision requires a shifting from developing innovation and products towards creating new systems [37]. In addition, they should not have their focus only on the organization but also on a wider range of stake- 
holders in order to create a broader value-add network and transform the entire company $[38,39]$.

Once sustainable practices and procedures are implemented, the company can also initiate some sustainable practice and procedures into their PDP. This will allow a changing culture towards sustainability within the entire organization. As a consequence, the initial focus is on the organization and its relation with its stakeholders towards sustainability rather than on its PDP.

In this paper, the maturation process is understood as successive stages of acquiring knowledge and developing innovation in which sustainable aspects are incorporated, not necessarily simultaneously and uniformly, within the entire organization. It depends on the people who are taken part of the process, once it is a process of cultural changing.

It is believed that companies have different levels of maturity in terms of implementation of environmental issues within their daily managerial procedures. Therefore, we proposed a theoretical classification according to these levels of maturity once they are hardly identified and formalized. This classification is described into details as follows:

\subsection{Complete immature companies: type 1}

It can be said that these companies are considered to be "completely immature" in terms of their engagement on sustainable issues. For this group of companies, ecodesign has not been implemented at all and they are still struggling to find out on how to cope with social environmental problems.

At this stage the company is pressured by different stakeholders. These include customers' demands, shareholders, government, legislation and regulations (local, national or global), competitors, financial partners, unions, NOG's, suppliers and the society in general. Normally, companies' type 1 is not concerned on social environmental issues at all. Their normal practices are more related to profitability, cost reduction and production efficiency. As a consequence, they usually have a reactive posture towards social environmental issues and consider them as an "another inconvenient aspect to be managed and increase costs". This means that social environment issues are consider as being a barrier for their businesses and not an opportunity for market growth and increasing profitability.

In addition, these companies have a short vision of their future and all of their efforts are spent on dealing with daily operational drawbacks rather than having a more strategic approach for their businesses. Therefore, their efforts on ecodesign are very rare and probably none or few attempts have been made to include environmental concerns in their product development process.

To move from company type 1 to company type 2 , the organization needs to consider some initial social environ- mental projects to improve its procedures (usually these projects are outsourced).

\subsection{Immature companies: type 2}

In the case of "immature" companies, some ecodesign projects may have already started, but they are very timid and no serious engagement from these companies has been observed so far. Generally, these projects are carried out by an external designer and they are not integrated into company's product development and production site.

Suffering the same pressure as companies' type 1, companies' type 2 have already started some timid experience on ecodesign. However, these companies still have the same reactive posture towards social environmental concerns as companies' type 1 and they see these experiences as a "rare market opportunity" to make profit on "green product" at that particular moment. This means that ecodesign has not been fully integrated into the product development process and environmental issues are seen as a unique opportunity to differentiate their products from their competitors. Therefore, these companies are still more concern on profitability, cost reduction and production efficiency issues rather than environmental aspects. However, they have already wakened up for new social environment market opportunities and try to experience few projects in this field.

Probably, these experiences are motivated by initial market opportunities and/or pressure from competitors and new environmental legislation. In addition, it is observed that these experiences are carried out with the help of external consultants who do not have a fully understanding of companies' operational procedures. As a consequence, products are developed independently from decisions taken at company's production site. Therefore, some small operational problems may occur in areas such as manufacturing and assembling. Nevertheless, it is a start and if successfully implemented, these experiences can help these companies to fully integrate ecodesign in their product development management procedures in the near future.

The step further, in terms of maturity, starts when the company begins to develop some "in-house" projects associated to social and/or environmental concerns.

\subsection{Initial mature companies: type 3}

These companies reached the point of "Initial maturation". This means that they have some "in house" sustainable projects. Ecodesign is integrated with company's production site and they may be working based on "simultaneous engineering" approach.

It can be noticed that in this case, the ecodesign process is now internally carried out within the company. In other words, ecodesign is now integrated into the product devel- 
opment process of the company. This means that the product development is integrated to the production process and management procedures such as simultaneous engineering may be used to reduce re-work. Also, it is perceived that sustainable issues are taken into account either on production level as well as on product development level. Finally, it can assume that environmental concerns are now taken into account at strategic level as well as part of the company's vision of the future.

This means that these types of companies have a more pro-active posture than companies' type 1 and 2 . In addition, environmental issues are now considered as a market opportunity for these companies and they are keen to integrate these aspects as part of their daily normal management procedures.

As any other company, at any stage of sustainable maturation, these companies are still concern on profitability, cost reduction and production efficiency issues. However, they evolve to a point on which environmental issues play an important role on their decisions and should be taken into consideration regardless strategic, management or operational issues.

To move to the next step of the sustainable maturity process, the organization needs to stimulate its suppliers to also consider sustainable issues in their daily decisionmaking process.

\subsection{Mature companies: type 4}

For this type of company, they reach the point where environmental concerns have been taken into account at operational, management and strategic levels as well as during its product development process. It is the level of "Maturation". In other words, companies are seen as "mature companies" in terms of introduction of ecodesign and social environmental issues into their daily procedures. As a consequence, suppliers are stimulated to participate in this process by considering environmental aspects within their daily procedures.

For companies' type 4 as for companies' type 3, ecodesign is already fully integrated into their product development process. Moreover, sustainable issues are part of their daily decision procedures (at operational, management and strategic level). However, in the case of companies' type 4, the suppliers have already been stimulated to also include social environmental concerns on their procedures. This means that social environmental performance will be used as one of strong the criteria for choosing their suppliers.

A positive consequence is that this will affect management decisions downstream on the supply chain. In other words, more companies (the suppliers) will have to take into account social environmental issues when developing their own products and services. It is like a "domino effect" on the downstream of the entire supply chain.
In addition, companies' type 4 may include on their criteria a sort of "social and environmental performance" for their suppliers forcing these companies to prove that they are seriously considering environmental issues on their business procedures.

As a result, it can be said that companies' type 4 have a pro-active posture towards social environmental issues as well as these issues are seen as "unique market opportunity" for them to definitely take off in the marketplace.

To move from company type 4 to company type 5 , the organization needs to "educate" their customers to consider social environmental aspects during their consume decisions.

\subsection{Maturated and teaching companies: type 5}

Companies from this group have not only taken on board their suppliers to consider environmental issues on their businesses decisions but also they have "educate" their customers to consider social environmental aspects during their consume decisions as well as integrated these demands by using marketing approaches and creating a new type of customer vision regarding their consumer behavior. It is considered that this process is "fully maturated" within the company and all of its procedures have taken into account social environmental concerns.

In this case, customers' demands and marketing procedures have been taken place. In other words, once ecodesign has already been fully integrated into their product development process and social environmental issues have been incorporated important issues of daily decision procedures (at operational, management and strategic level), the company starts to close its relationship with their customers as well as tries to "educate" them towards a more social environmental conscious consumer behavior. This means that the company starts to develop new marketing procedures, improve its approaches to have a closer relationship with its customers in terms of environmental concerns as well as develop new forms of commercial relationship with its customers.

At this stage, new commercial approaches can be incorporate into company's commercial strategy. In some cases, companies have to convince their customers about the advantages of changing the way they relate with company's products and services. In this case, the information feedback collected from customers can passed on to the entire supply chain of the system involving a complete loop of information exchange among customers, companies and supply chain.

This will give a futurologist vision on how social environmental concerns will influence business performance and what procedures companies will have to develop to achieve a complete "sustainable business approach". This means that new technologies, management procedures, marketing procedures, products and services will be develop to fulfill the 
requirements of this new "responsible consumer". These companies have a completely pro-active posture towards social environmental issues and their visionary posture towards future will change the way we consume goods and services.

And finally, to move from company type 5 to company type 6 , it requires an integration of many organizations which make business among themselves considering social environmental concerns as the most important aspect for them during theirs decision making process.

\subsection{Integrated companies: type 6}

Companies' type 6 are also considered to be "fully maturated" as in the case of companies' type 5. However, in this case, they have reached to a point on which social and environmental issues are the most important criteria for them to do business among themselves. They exchange sustainable experiences as well as stimuli their business partners to do the same, creating an integrated network of "sustainable companies".

At this point, companies trade with each order considering social and environmental aspects as well as searching solutions for a fully sustainable integration. They work for market which is fully conscious regarding their consume behavior and they develop new products and services to meet the demands of this new market.

This paper assumes that this evolutional process of integrating sustainable issues within the company can be improved by embedding these aspects at all corporate hierarchical levels, from global strategic decisions (top management), through planning and organization (tactical management), to daily engineering design and production activities (operational area). To improve the introduction of environmental aspects within the product design, it is necessary to consider the global company objectives, the organizational aspects, and the relationship with stakeholders, as well as competences and real design collaborative processes. The environmental improvement objectives involved at the strategic level should be fulfilled at product level. Conversely, objectives considered at product level might also bring a visible influence from the operational level on strategic decisions. This is a closed-looping collaborative process among the entire organization which will help for better integrating sustainable issues within the design process. The authors have chosen to demonstrate this assumption by proposing a maturity framework as stated in the following section.

\section{Maturity framework proposal}

The proposed framework is based on a questionnaire on which decision-makers from different areas of the organi- zation at strategy, tactical and operational levels will judge a series of statements according to their opinion. Each group of statements is classified according to 12 different categories of indicators, named as: company's strategic vision; company's values; company's general policy; top management commitment; company relationship with stakeholders; company's purchasing policy; company's economic indicator performance; company's environmental indicator performance; company's social indicator performance; environmental communication; legislation; standards and company's "green" marketing procedures.

To each judgment given by the decision-makers, a number of points is associated to the statement as follows: (a) when the respondent strongly agrees with the statement (I strongly agree: +2 points); (b) when the respondent agrees with the statement (I agree: +1 point); (c) when the respondent disagrees with the statement (I disagree: -1 points); (d) when the respondent strongly disagrees with the statement (I strongly disagree: -2 points), and; (e) when the responded does not have an opinion (I do not know: 0 points). For instance, if the indicator $\mathrm{X}$ is composed by four statements, the indicator will range from -8 points (i.e. -2 points vs. 4 statements) to +8 points (i.e. 2 points vs. 4 statements).

However, each decision-maker of the company has different views and is interested in different indicator. Therefore, instead of using a range of points, one must normalize each indicator by dividing its value by the maximum number of points in which it can be achieved (in this particularly case, 8 points). Therefore, a normalized indicator will range in a scale from -1 to +1 .

Therefore, using the scale from -1 to +1 , it can be said that if an indicator $i$ reaches the value +1 , then the company is considered "totally committed" (TC) to the specific issues of the indicator $i$. On the other hand, if an indicator $i$ reach the value -1 , then the company is considered "totally uncommitted" (TU) to this specific issues of the indicator $i$. Similarly, if an indicator $i$ reach the value +0.5 , it can be said that the company is considered "partially committed" (PC) to the specific issues of the indicator $i$ and if an indicator $i$ reach the value -0.5 , it can be said that the company is considered "partially uncommitted" (PU) to the specific issues of the indicator $i$. In addition, companies can also be considered "nearly committed" (NC) if an indicator $i$ reach any value between +0.5 and +1 or "nearly uncommitted" (NU) if an indicator $i$ reach any value between -0.5 and -1 . Also, companies can be considered "nearly indifferent" (NI) if an indicator $i$ reach any value between 0 and +0.5 or between 0 and -0.5 . Finally, if the indicator $i$ reach the value 0 , the company is considered "indifferent" (I) to the specific issues of the indicator $i$.

Similarly, companies have different strategies of sustainable development and they focus on different indicators attributing different weights to individual indicator. There- 
Table 1 Relationship between index and company type

\begin{tabular}{ll}
\hline Index $I$ & Company type \\
\hline-1 to 0.0 & 1 \\
$>0.0$ to 0.2 & 2 \\
$>0.2$ to 0.4 & 3 \\
$>0.4$ to 0.6 & 4 \\
$>0.6$ to 0.8 & 5 \\
$>0.8$ to 1.0 & 6 \\
\hline
\end{tabular}

fore, if necessary, the next procedural part it would be calculating a generic index $I$ which involves determining weights combined with each indicator. As a consequence, it is suggested the use of the analytic hierarchy process (AHP) [40]. The weight of each indicator can be delivered by the prioritization of their impact to the overall sustainability assessment of the company. Therefore, let us assume that $N$ indicators of sustainable development are being considered with the goal of providing and quantifying judgments on the relative weight of each indicator with respect to all the other indicators. The first step is to set up the overall sustainability assessment of the company hierarchically, where the topmost aspect $X$ is the main objective of the company, while subsequent aspects at lower levels consist of the criteria used in arriving at this overall sustainability assessment. The second step requires pair-wise comparisons to be made between each pair of indicators (of the given level of the hierarchy). The comparisons are made by posing the question which of the two indicators $i$ or $j$ is more important with respect to the sustainable development of the company, respectively. For instance, the intense of preference can be expressed on a factor scale from 1 to 9 as suggested by Hafeez et al. [41]. This scale was chosen, because in this way comparisons are being made within a limited range where perception is sensitive enough to make a distinction.

Once all weights are determined for each indicator, a weighted arithmetic mean can be used to calculate the generic index $I$. Again, this index will range from -1 to +1 . This means that the closer is the index $I$ to value -1 , the more uncommitted is the company to sustainable issues. On the contrary, the closer is the index $I$ to value +1 , the more committed is the company to sustainable issues.

As a consequence, it is possible to interpret the final result of index $I$ according to the classification presented in Sect. 5.1 to 5.6 as indicated in Table 1.

Therefore, the analysis will help decision-makers to consider each one of the 12 indicators separately as well as a generic index. As a consequence, companies will have the opportunity to evaluate their performance against important issues for sustainability individually as well as a global evaluation regarding sustainability in a holistic manner.

\subsection{Initial test and validation}

In order to test and validate our framework, ten medium to large size manufactured companies from various sectors (e.g. automotive and heavy goods vehicle, high and mediumvoltage products, camping gear and outdoor equipment, kitchen furniture, light sport airplanes, pharmaceuticals and so on) were randomly selected and contacted. As a consequence, members form these companies were invited to answer the questionnaire as well as complete the framework.

These members were chosen due to their managerial position within the company as well as their general overview of its procedures (e.g. product design managers, $R \& D$ managers and manufacture managers).

Initial results have indicated that the implementation of environmental aspects within companies does not necessarily follow a logical pathway. For some companies, environmental operational procedures are well established (i.e. mature) and some managerial environmental procedures are still in process of implementation (i.e. immature) while to others this process is inverse.

In addition, there is no apparent connection to the different categories of indicators. In other words, there is no connection between one indicator to another. For instance, "top management commitment" is not necessarily related to "company's values" or "company's general policy".

Companies have difficulties to deliver holistic changes necessary to achieve a long-term sustainability in order to remain competitive. They should firstly improve their strategy and management skills towards sustainability before introducing any ecodesign tool.

\section{Conclusions}

Companies have difficulties to deliver holistic changes necessary to achieve a long-term sustainability in order to remain competitive. They should firstly improve their strategy and management skills towards sustainability before introducing any ecodesign tool.

It requires a collaborative work among the entire organization involving not only the three levels of the company (strategic, tactical and operational) but also all its stakeholders. In general, it is a cultural change within the entire organization towards sustainability.

The self-evaluation framework proposed in this paper aims to rank companies into different classes according to their level of maturity in terms of sustainability. It is a complementary work to other models already existent in the literature. For instance, it can be used as a first step stage to before implementing the Ecodesign Maturity Model proposed by Pigosso [19]. At a more advanced stage, this simple and practical framework will facilitate a changing on 
the "culture environment" within the company, making it more suitable towards sustainability. Therefore, more complex models of sustainable integration within companies such as the "Convergence" Research Project [42] can be implemented.

This "Convergence" model aims to integrate sustainability into the three levels. At the strategic level, it proposes a diagnosis of the current situation within the company to define sustainable strategies which can aid with the maturities grids of integration and governance. At the tactical level, a pilot assistance and optimization tool by offering roadmaps (selection of methods, resources and initial steps) adapted to the context of the company, embodied in an action plan. And finally, at the operational level to identify ecodesign actions to be taken and tools to be used at each stage of the PDP and promote an exchange of information between business experts within the PDP.

Acknowledgments The authors would like to thank the Direction de L'Enseignement Superior de la Recherhe et de L'Innovation, Region Champagne-Ardene and the École National Supérieure d'Arts et Métiers for the financial support of this research.

\section{References}

1. Grüninger, B.: In: GRI - Caminhos e desafios para relatórios de sustentabilidade. Business meets social development. Available from: http://www.ahkbrasil.com/upload_arq/BSD_GRI_Geral_ 20071023.pdf, (2008)

2. Hart, S.L., Milstein, M.B.: Creating a sustainable value. Acad. Manag. Excutive 17, 56-69 (2003)

3. Jackson, T.: Motivating Sustainable Consumption: a Review of Evidence on Consumer Behaviour and Behavioural Change. In: A Report to the Sustainable Development Research Network. Centre for Environmental Strategy, University of Surrey (2004)

4. ERSCP.: Meeting consumer demand for sustainable products. In: Summary of the workshop.12-14 May:Bilbao (2004). Available from: http://www.erscp2004.net/FinalReport.htm

5. Barbieri, J.C.: Desenvolvimento e meio ambiente: as estratégias de mudança da agenda 21. Vozes, Petrópolis (2004)

6. Medeiros, J.F., Ribeiro, D.J.L., Cortimiglia, M.N.: Sucessful factors for environmentally sustainable product innovation: a systematic literature review. J. Clean. Prod. 65, 76-86 (2014)

7. Cross, N.: Engineering design methods: strategies for product design, 2nd edn. Wiley, Chichester (1994)

8. Stubbs, W., Cocklin, C.: Conceptualizing a sustenability business model. Org. Environ. 21(2), 172-194 (2008)

9. Wells, P., Seitz, M.: Business model and close-loop supply chains: a typology. Supply Chain Manag. Int J. 10(3-4), 249-251 (2005)

10. Hawken, P., Lovins, A.B., Lovins, L.H.: Natural capitalism: the next industrial revolution effect. Palgrave Macmillan, Basingstoke (2005)

11. Grassi, W.: Business models of social enterprise: a design approach. ACRN J Entrep. Perspect. 1(1), 37-60 (2012)

12. Tukker, A.: Eight steps of product-service system: eight ways to sustainability? experiences from suspronet. Bus. Strategy Environ. 13(4), 246-260 (2004)
13. Mont, O., Tukker, A.: Product-service systems: reviewing achievements and refining the research agenda. J Clean. Prod. 1454(17), 1451-1451 (2006)

14. Pauli, G.: The blue economy: 10 years, 100 innovations, 100 million jobs. report to the club of Rome. Paradigm Publications, New Mexico (2010)

15. Baines, T., Lightfoot, H., Evans, S., Neely, A., et al.: State-of-the-art in product-service systems. Proc. Inst. Mech. Eng. J. Eng. Manuf. 221(10), 1543-1552 (2007)

16. Boken, N.M.P., Short, S.W., Rana, P., Evans, S.: A literature and practice review to develop sustainable business model archetypes. J Clean. Prod. 65, 42-56 (2014)

17. Zhang, F., Rio, M., Allais, R., Zwolinski, P., Carrillo, T.R., Roucoules, L., Mercier-Laurent, E., Buclet, N.: Towards a systematic navigation framework to integrate sustainable development into the company. J Clean. Prod. 254, 199-214 (2013)

18. Cheng, Y.S.: The driver of green innovation and green image-green core competence. J. Bus. Ethics 543(3), 250-531 (2007)

19. Pigosso, D.C., Rozenfeld, H., McAloone, T.C.: Ecodesign maturity model: a management framework to support ecodesign implementation into manufacturing companies. J. Clean. Prod. 59, 160-173 (2013)

20. Xu, Y., Bernard, A., Perry, N., Xu, J., Sugimoto, S.: Knowledge evaluation in product lifecycle design and support. Knowl. Based Syst. 70, 256-267 (2014)

21. Drémont, N., Troussier, N., Whitfield, R.I., Duffy, A.: A metamodel for knowledge representation integrating maturity for decision making in engineering design. In: Bernard, A., Rivest, L., Dutta, D. (eds.) Product lifecycle management for society, pp. 385395. Springer, Berlin (2013)

22. Perry, N., Bernard, A., Bosch-Mauchand, M., Le Duigou, J., Xu, Y.: Proposal of an architectural solution for economic and environment global eco-cost assessment: models combination analysis. Chapter 12 In: Technology and Manufacturing Process Selection: the Product Life Cycle Perspective. Springer Berlin, pp. 239-56 (2014)

23. Engert, S., Rauter, R., Baumgartner, R.J.: Exploring the integration of corporate sustainability into strategic management: a literature review. J. Clean. Prod. 112(part 4), (2016)

24. Mintberg, H.: Management Science, 24(9), (1978)

25. Salzmann, O., Ionescu-Somers, A., Steger, U.: The business case for corporate sustainability: literature review and research options. Eur. Manag. J. 23(1), 27-36 (2005)

26. Rossi, M., Germani, M., Zamagni, A.: Review of ecodesign methods and tools. Barriers and strategies for an effective implementation in industrial companies Journal of Cleaner Production, Accepted Manuscript, April, (2016)

27. Blessing, L., Chakrabarti, A.: DRM, a design research methodology. Springer, London (2009)

28. United Nations Commission on Sustainable Development.: Indicators of sustainable development: guidelines and methodologies. United Nations, (2001). Available from: http://www.un.org/esa/ sustdev/publications/indisd-mg2001.pdf

29. IChemE.: The sustainability metrics: sustainable development progress metrics recommended for use in the process industries. Warwickshire: Institution of Chemical Engineers (2002)

30. Sapangenberg, J.H., Bonniot, O.: Sustainability indicators-a compass on the road towards sustainability. Wuppertal Paper (81), (1998)

31. CSRHub: (2015). Available from: http://www.csrhub.com/

32. GRI.: Sustainability reporting guidelines. Boston (MA): Global Reporting Initiative (2002)

33. Bocken, N.M.P., Short, S.W., Rana, P., Evans, S.: A literature and practice review to develop sustainable business model archetypes. J. Clean. Prod. 65, 42-56 (2014) 
34. Carlson, R.C., Rafinejad, D.: Modelling sustainability in product development and comercialization. Bull. Sci. Technol. Soc. 28(6), 478-485 (2008)

35. Hynds, E.J., Brandt, V., Burek, S., Jager, W., Knox, P., Parker, J.P., Schwartz, L., Taylor, J., Zietlow, M.: A Maturity Model for Sustainability in New Product Development. Research-Technology Management, January-February (2014)

36. Amit, R., Zott, C.: Creating value through business model innovation. MIT Sloan Manag. Rev. 53(3), 41-49 (2012)

37. Johnson, M., Suskewicz, J.: How to Jump-Start the Clean Tech Economy. Harvard Business Review. November: pp. 52-60 (2009)

38. Beattie, V., Smith, S.: Value creation and business models: refocusing the intellectual capital debate. Br. Account. Rev. 45(4), 243-254 (2013)
39. Zott, C., Amit, R., Massa, L.: The business model: recent developments and future research. J. Manag. 37(4), 1019-1042 (2011)

40. Saaty, T.L.: Analytical hierarchy process: planning, priority setting, resource allocation. McGraw-Hill, New York (1980)

41. Hafeez, K., Zang, Y., Malak, N.: Determining key capabilities of firm using analytic hierarchy process. Int. J. Prod. Econ. 76, 39-51 (2002)

42. Zhang, Feng Rio, Allais, Mauro, Romain, Zwolinski, Peggy, Carrillo, Tatiana, Reyes, Roucoules, Lionel, Mercier-Laurent, Eunika, Buclet, Nicolas: Towards a systematic navigation framework to integrate sustainable development into the company. J. Clean. Prod. 54, 199-214 (2013) 